\title{
Desorption Chemical Ionization Mass Spectra of Underivatized Abscisic Acid-conjugated Metabolites, a Useful Aid for Structural Characterization
}

\author{
Naohito Takeda, Ken-ichi Harada, Makoto Suzuki, ${ }^{\dagger}$ \\ Akira TAtematsu, Nobuhiro HiRaI* \\ and Koichi KoshimizU* \\ Faculty of Pharmacy, Meijo University, Tempaku, Nagoya 468, Japan \\ * Faculty of Agriculture, Kyoto University, Kyoto 606, Japan
}

Received March 11, 1986

\begin{abstract}
The use of desorption chemical ionization $(\mathrm{D} / \mathrm{CI})$ mass spectrometry for the structural characterization of the abscisic acid (ABA)-conjugated metabolites, abscisic acid- $\beta$-D-glucosyl ester (ABAGE), 4 '- $O$-dihydrophaseic acid- $\beta$-D-glucoside (DPAGS) and $\beta$-hydroxy- $\beta$-methylglutarylhydroxyabscisic acid (HMG-HOABA), was studied. The effects of the D/CI source temperature on the spectral features are described. Enhanced quasi-molecular ion intensities (e.g., $\left[\mathrm{M} \cdot \mathrm{NH}_{4}\right]^{+}$) were observed in the $\mathrm{D} / \mathrm{CI}\left(\mathrm{NH}_{3}\right)$ spectrum at a low source temperature $\left(170^{\circ} \mathrm{C}\right)$. When a higher source temperature $\left(250^{\circ} \mathrm{C}\right)$ was used, more extensive fragmentation occurred, and structurally diagnostic fragment ions appeared in the spectra. The spectra obtained at two degrees of source temperature were complementary to each other for the structural characterization.
\end{abstract}

In metabolic studies of the plant hormone abscisic acid (ABA), considerable attention has been drawn to the conjugated form, because the levels of free ABA and its conjugate in plant organs are closely correlated with physiological processes. ${ }^{1 \sim 5)}$ In a previous paper, we demonstrated that chemical ionization mass spectrometry (CIMS) provided an effective technique for characterizing the structural features of small quantities of ABA and related metabolites. ${ }^{6}{ }^{6}$ However, the highly polar nature of the conjugates required derivatization procedures before CIMS analysis. ${ }^{4 \sim 6)}$ Additional sample consumption was unavoidable during the derivatization and/or chromatographic purification steps. This problem is serious, because the amount of material is usually limited.

Desorption chemical ionization $(\mathrm{D} / \mathrm{CI})$ mass spectrometry has been considered as one of the most promising methods for such involatile compounds. $^{7 \sim 9)}$ The technique is characterized by the use of an FD-like emitter as a solid probe, which is close to the electron beam of a CI source. ${ }^{10)}$ We recently demonstrated that U-shaped coiled-wire emitters were highly efficient and well suited as $\mathrm{D} / \mathrm{CI}$ probes. ${ }^{8)}$ Several commercial $\mathrm{D} / \mathrm{CI}$ probes are now available.

The objective of this work was to develop a rapid and convenient means for characterizing ABA-conjugated metabolites (ABAGE, $\mathbf{1} ;{ }^{11)}$ DPAGS, 2; ${ }^{5,12)}$ HMG-HOABA, $\left.3^{13)}\right)$. ${ }^{* 1}$ We now report a successful attempt to obtain structural information from the underivatized conjugates at a $1 \mu \mathrm{g}$ sample size using the $\mathrm{D} / \mathrm{CI}$ method with ammonia and ammonia- $d_{3}\left(\mathrm{ND}_{3}\right)$ as reagent gases.

\footnotetext{
+ Author to whom correspondence should be addressed.

Abbreviations: ABAGE, abscisic acid- $\beta$-D-glucosyl ester; DPAGS, $4^{\prime}$ - $O$-dihydrophaseic acid- $\beta$-D-glucoside; HMGHOABA, $\beta$-hydroxy- $\beta$-methylglutarylhydroxyabscisic acid.

*1 The problem concerning the differentiation of stereoisomers has not been solved in the present studies because of the lack of a pair of stereoisomers.
} 


\section{RESULTS AND DISCUSSION}

The $\mathrm{D} / \mathrm{CI}\left(\mathrm{NH}_{3} / \mathrm{ND}_{3}\right)$ mass spectra of the conjugates $(\mathbf{1} \sim \mathbf{3})$ are given in Figs. $1 \sim 3$, and show a general similarity to the conventional CI spectra, with quasi-molecular ions, and aglycone- and sugar-derived ions all being present. ${ }^{6}$ ) The $\mathrm{D} / \mathrm{CI}\left(\mathrm{NH}_{3}\right)$ mass spectra were recorded at two degrees of source temperatures $\left(170^{\circ} \mathrm{C}\right.$ and $\left.230^{\circ} \mathrm{C}\right)$, and the effects on fragmentation of the ion source temperature are briefly described.

\section{D/CI mass spectra of $A B A G E$ (1)}

A comparison of the $\mathrm{D} / \mathrm{CI}\left(\mathrm{NH}_{3}\right)$ mass spectra taken at low and high source temperatures demonstrates the qualitative effect of the source temperature on the mass spectral pattern (Figs. 1a and 1b). Molecular weight information could be readily obtained via molecular adduct ion species, particularly in the spectrum obtained at the lower source temperature, where $\left[\mathrm{M} \cdot \mathrm{NH}_{4}\right]^{+}(m / z 444)$ was the base peak together with $\left[\mathrm{M} \cdot \mathrm{NH}_{3} \mathrm{NH}_{4}\right]^{+}(\mathrm{m} / z$
461). The occurrence of a metastable transition $(m / z$ 461 $\rightarrow m / z$ 444; loss of an ammonia from $\left[\mathrm{M} \cdot \mathrm{NH}_{3} \mathrm{NH}_{4}\right]^{+}$) provided further support in the complete molecular weight determination. The $\left[\mathrm{M} \cdot \mathrm{NH}_{4}\right]^{+}$ion at the higher source temperature was relatively weak, but well-defined in the spectrum, where several intense fragment ions were observed.

The ions at $m / z$ 282, 198 and 180 correspond to aglycone- and the sugar-derived ions formulated as $\left[\mathrm{A} \cdot \mathrm{OH}+\mathrm{NH}_{4}\right]^{+},\left[\mathrm{S} \cdot \mathrm{OH}+\mathrm{NH}_{4}\right]^{+}$ and $\left[\mathrm{S} \cdot \mathrm{NH}_{3}\right]^{+}$, respectively. These ions have originated in characteristic fragmentations, as has been observed under conventional CI conditions. ${ }^{6}$ ) On the other hand, the spectrum taken at the lower source temperature was dominated by more extensive ammonium adduct-complexes, where $\left[\mathrm{A} \cdot \mathrm{OH}+\mathrm{NH}_{3} \mathrm{NH}_{4}\right]^{+}$ $\left(m / z\right.$ 299), $\left[\mathrm{S} \cdot \mathrm{OH}+\mathrm{NH}_{3} \mathrm{NH}_{4}\right]^{+} \quad(m / z \quad 215)$ and $\left[\mathrm{S} \cdot \mathrm{NH}_{3} \mathrm{NH}_{3}\right]^{+}(m / z$ 197) newly appeared. These structurally diagnostic ions probably arose from ammonium attachment at the glycosidic oxygen and followed by glycosidic bond cleavage as illustrated in Fig. 4.

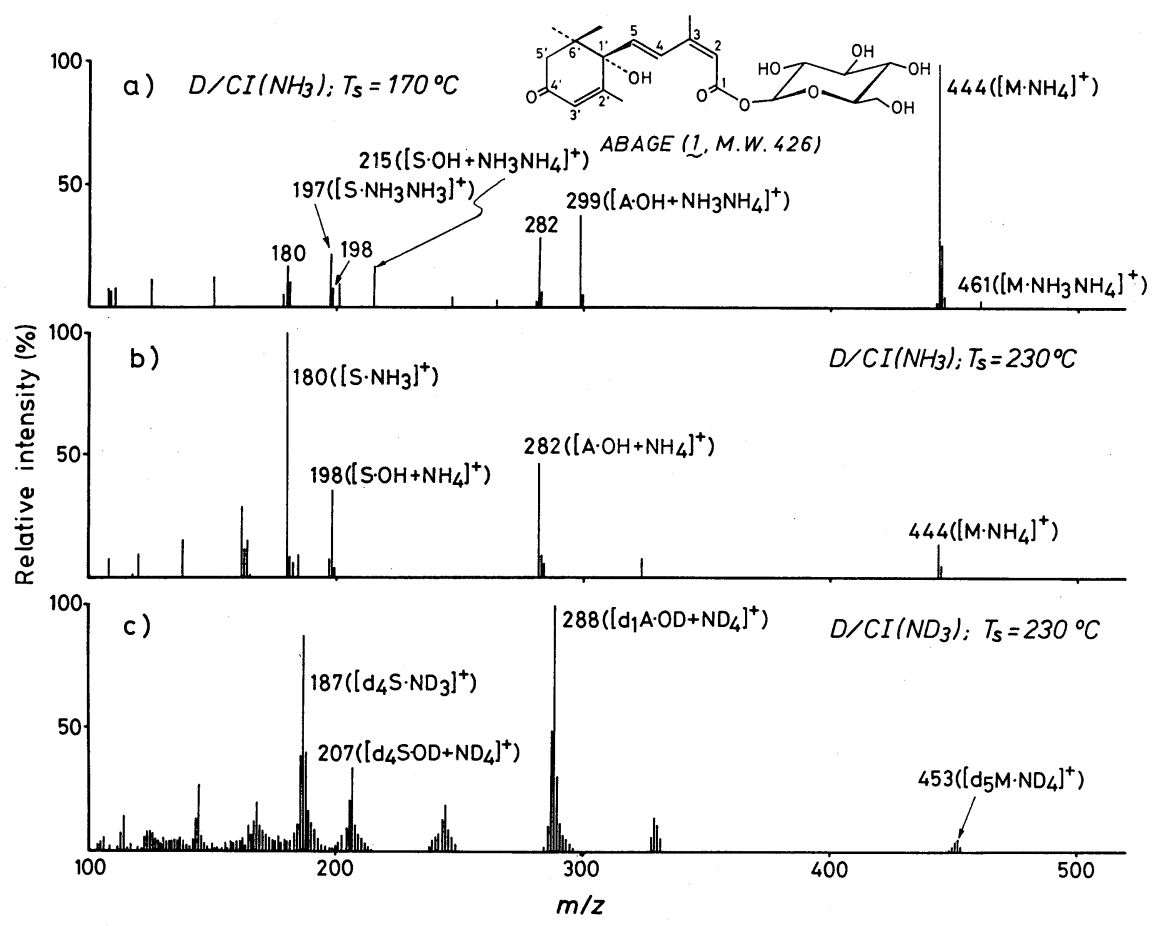

FIG. 1. D/CI Mass Spectra of ABAGE (1) Using Ammonia and Ammonia- $d_{3}$ as Reagent Gases. 


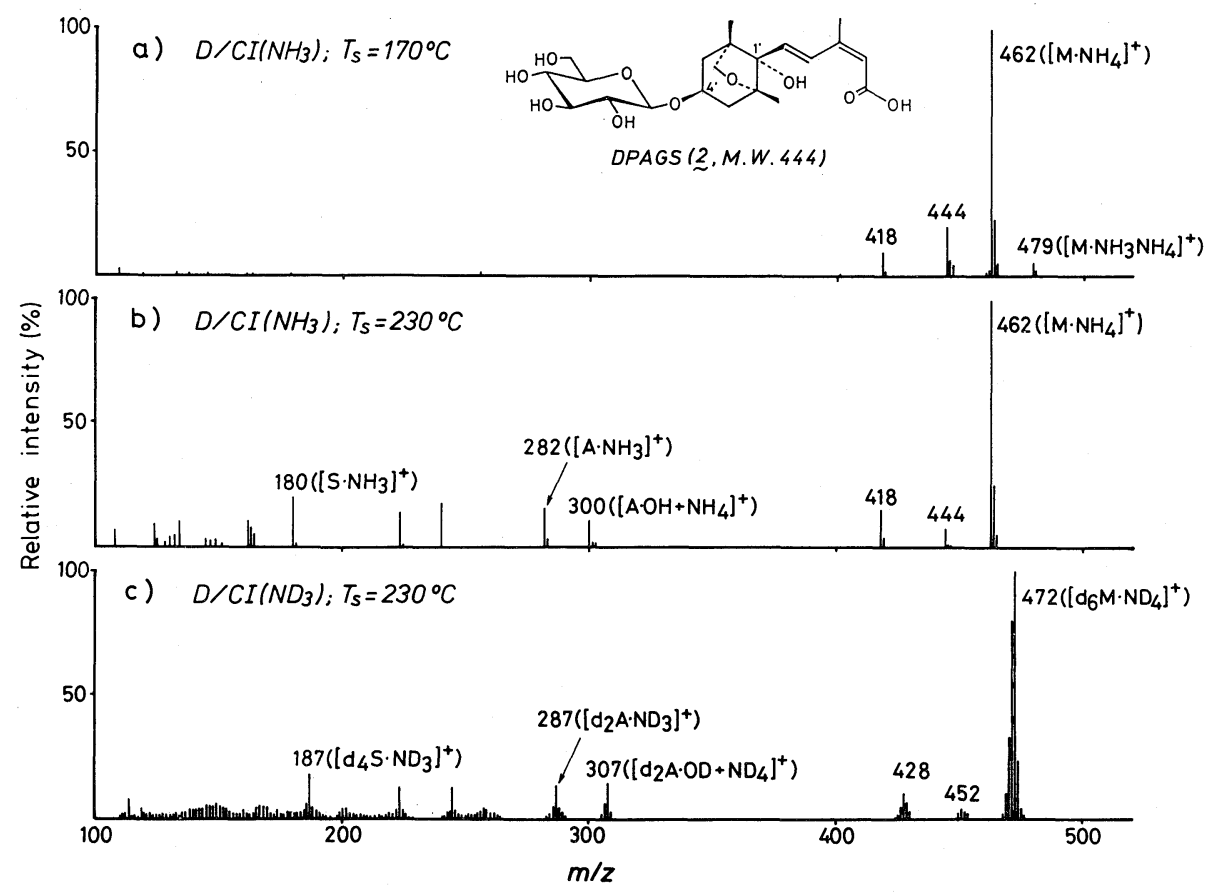

FIG. 2. D/CI Mass Spectra of DPAGS (2) Using Ammonia and Ammonia- $d_{3}$ as Reagent Gases.

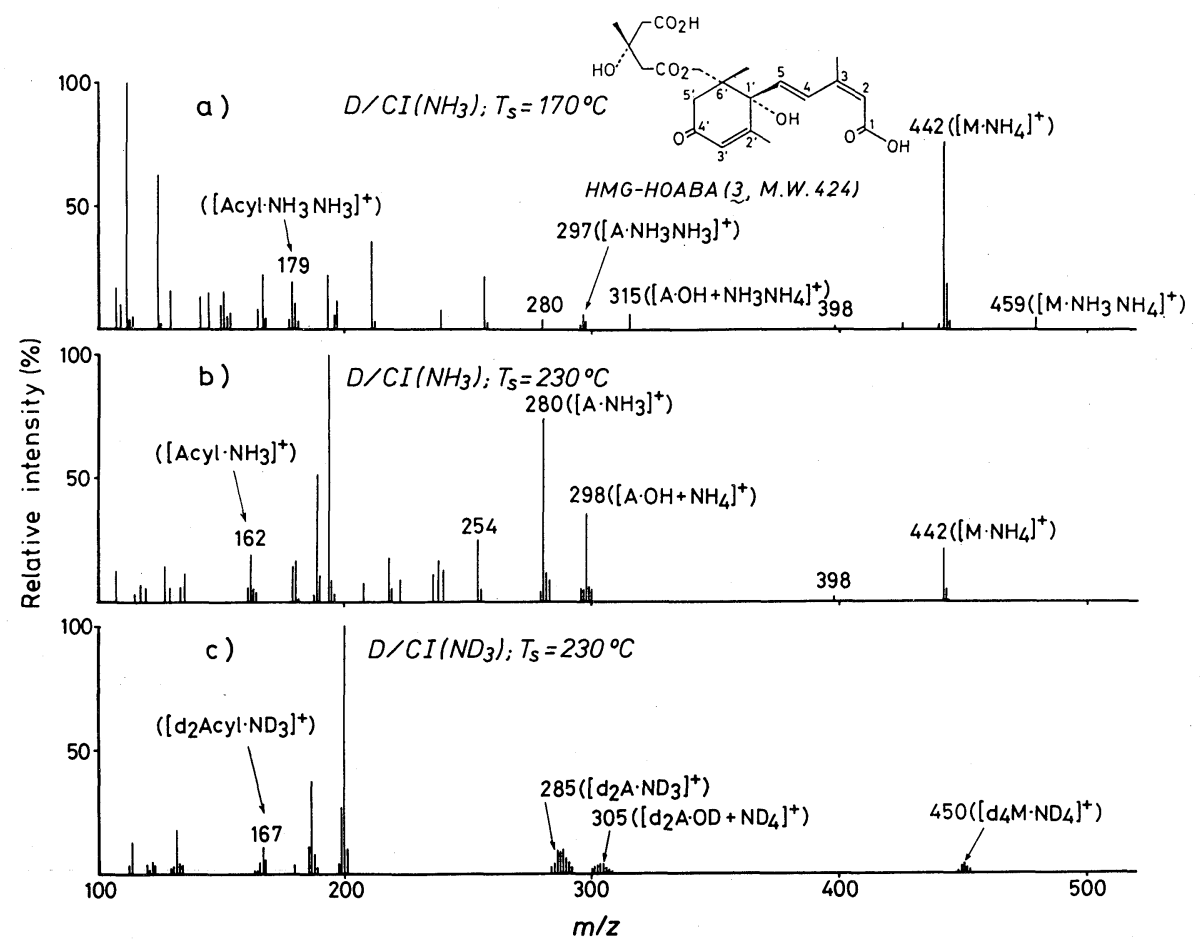

Fig. 3. D/CI Mass Spectra of HMG-HOABA (3) Using Ammonia and Ammonia- $d_{3}$ as Reagent Gases. 


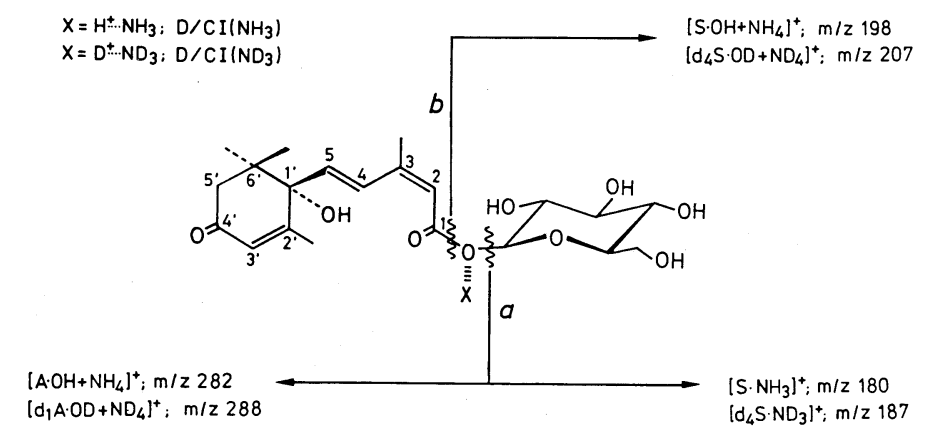

FIG. 4. Diagnostic Fragment Ions in the D/CI Mass Spectra of ABAGE (1).

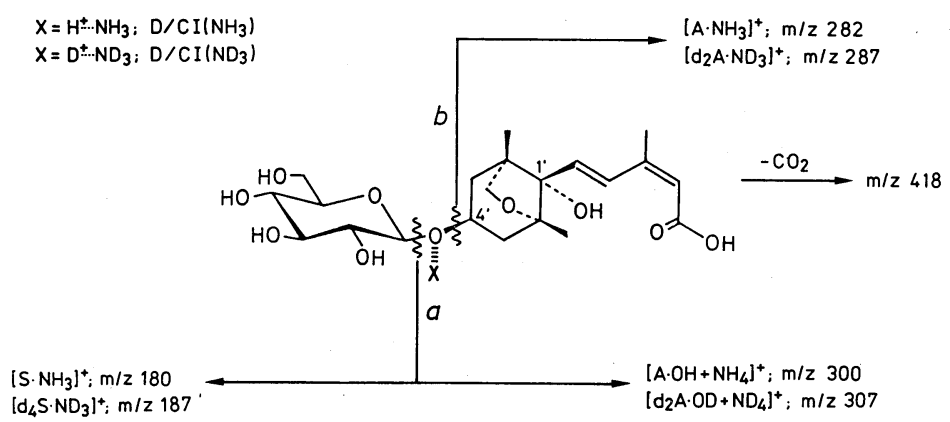

FIG. 5. Diagnostic Fragment Ions in the D/CI Mass Spectra of DPAGS (2).

The use of the shift technique with ammonia$d_{3}$ was desirable for confirming the fragmentation pathways and for assigning the resulting fragment ion species with more confidence. ${ }^{14)}$ The deuterated analogous species as a result of the gas phase H-D exchange process, formulated as $\left[d_{5} \mathbf{M} \cdot \mathrm{ND}_{4}\right]^{+}(m / z 453)$, $\left[d_{1} \mathrm{~A} \cdot \mathrm{OD}+\mathrm{ND}_{4}\right]^{+} \quad(m / z \quad 288), \quad\left[d_{4} \mathrm{~S} \cdot \mathrm{OD}\right.$ $\left.+\mathrm{ND}_{4}\right]^{+}\left(m / z\right.$ 207) and $\left[d_{4} \mathrm{~S} \cdot \mathrm{ND}_{3}\right]^{+}(m / z$ 187) are given in the $\mathrm{D} / \mathrm{CI}\left(\mathrm{ND}_{3}\right)$ mass spectrum (Fig. 1c).

\section{D/CI mass spectra of DPAGS (2)}

The D/CI mass spectrum obtained at low source temperature gives the molecular adduct ion, $\left[\mathrm{M} \cdot \mathrm{NH}_{4}\right]^{+}$at $m / z 462$ as the base peak, together with $\left[\mathrm{M} \cdot \mathrm{NH}_{3} \mathrm{NH}_{4}\right]^{+}$at $m / z 479$ (Fig. 2a). The fragment ion at $m / z 444$ was assigned to $\left[\mathrm{M} \cdot \mathrm{NH}_{4}-\mathrm{H}_{2} \mathrm{O}\right]^{+}$, which was presumably derived from the elimination of a 1'-hydroxy group rather than that of the hydroxy group of a carboxyl function, as has been ascertained by a comparable CI study on dihydrophaseic acid (DPA) and its related aglycones. ${ }^{6)}$ The ion at $m / z \quad 418$ was assigned to $\left[\mathrm{M} \cdot \mathrm{NH}_{4}-\mathrm{CO}_{2}\right]^{+}$. This fragmentation process is characteristic of free acids of this class and indicates the presence of a carboxyl group in the molecules. ${ }^{6)}$

Aglycone- and the sugar-derived ions can not be observed in the spectrum at lower source temperature (Fig. 2a), but these ions appear in the spectrum obtained at the higher source temperature (Fig. 2b); $\left[\mathrm{A} \cdot \mathrm{OH}+\mathrm{NH}_{4}\right]^{+}$ $(m / z 300),\left[\mathrm{A} \cdot \mathrm{NH}_{3}\right]^{+}(m / z 282)$ and $\left[\mathrm{S} \cdot \mathrm{NH}_{3}\right]^{+}$ $(m / z$ 180). The major fragmentation pathways are illustrated in Fig. 5, and are apparent from the appropriate mass shift in the $\mathrm{D} / \mathrm{CI}\left(\mathrm{ND}_{3}\right)$ mass spectrum (Fig. 2c).

\section{D/CI mass spectra of $H M G-H O A B A$ (3)}

The $\mathrm{D} / \mathrm{CI}\left(\mathrm{NH}_{3}\right)$ mass spectrum obtained at the lower source temperature is dominated by $\left[\mathrm{M} \cdot \mathrm{NH}_{4}\right]^{+}$at $m / z 442$ and $\left[\mathrm{M} \cdot \mathrm{NH}_{3} \mathrm{NH}_{4}\right]^{+}$at $m / z 459$ (Fig. 3a). The ion at $m / z 398$ repre- 


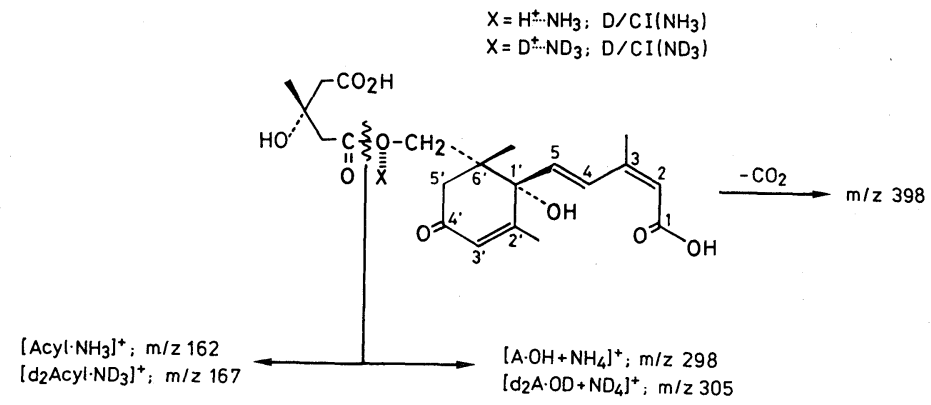

FIG. 6. Diagnostic Fragment Ions in the D/CI Mass Spectra of HMG-HOABA (3).

sents the expulsion of $\mathrm{CO}_{2}$ from the $\left[\mathrm{M} \cdot \mathrm{NH}_{4}\right]^{+}$, whose occurrence again indicates the presence of a carboxyl group in $\mathbf{3}$. Ions associated with the acyl moiety function were clearly observed when examined under the higher source temperature. The deacyl ion at $m / z 315\left(\left[\mathrm{~A} \cdot \mathrm{OH}+\mathrm{NH}_{4}\right]^{+}\right)$in Fig. $3 \mathrm{~b}$ can be accounted for by loss of a $\beta$-hydroxy- $\beta$ methylglutaryl moiety from the $\left[\mathrm{M} \cdot \mathrm{NH}_{4}\right]^{+}$.

It should be noted that the $\mathrm{D} / \mathrm{CI}$ mass spectrum contains the acylium ion ([Acyl. $\left.\mathrm{NH}_{3}\right]^{+}$) as the counterpart, because such an ion is absent in the conventional CI mass spectrum of the demethylester. ${ }^{6)}$ The $\mathrm{D} / \mathrm{CI}$ $\left(\mathrm{ND}_{3}\right)$ mass spectrum (Fig. 3c) again provides information for assigning the fragmentation process, as shown in Fig. 6.

In conclusion, $\mathrm{D} / \mathrm{CI}\left(\mathrm{NH}_{3} / \mathrm{ND}_{3}\right)$ mass spectrometry was proved to be a useful technique for the structural analysis of a small quantity of underivatized ABA-conjugated metabolites. A comparison of the spectra obtained at low and high source temperatures has a decided influence on the fragmentation. ${ }^{7)}$ In reality, molecular weight data could be easily obtained in the spectrum of a lower source temperature, while structural information was more available when the conjugates were analysed at a higher source temperature.

Therefore, applying low and high source temperatures is an effective procedure for unambiguously characterizing the conjugates.

\section{EXPERIMENTAL}

All mass spectra were obtained with a Shimadzu LKB
9000A mass spectrometer which had been modified for $\mathrm{D} / \mathrm{CI}$ operation. This modification and major procedures for recording the mass spectra have already been described. ${ }^{7,8)}$

The preparation of ABAGE (1), DPAGS (2) and HMG-HOABA (3) has been reported in previous papers. ${ }^{6,12,13)}$ The samples $(1 \sim 3)$ were dissolved in methanol at concentrations of $1 \mu \mathrm{g} \mu \mathrm{l}^{-1}$ and loaded with a $10 \mu \mathrm{l}$ syringe $(1 \mu \mathrm{l})$ onto the $\mathrm{D} / \mathrm{CI}$ emitter. The emitter current was increased at the rate of $2 \mathrm{mAs}^{-1}$ from 0 to $290 \mathrm{~mA}$. Typical operating conditions were as follows: accelerating voltage, $3.5 \mathrm{kV}$; electron energy, $150 \mathrm{eV}$; emission current, $120 \mu \mathrm{A}$; reagent gas pressure, 0.13 Torr. The reagent gases used, $\mathrm{NH}_{3}(99.95 \%$ purity) was purchased from Takachiho Trading Co. Ltd; and $\mathrm{ND}_{3}$ (99 atom $\%$ D) was obtained from Merck, Sharp and Dohme, Canada, Ltd.

\section{REFERENCES}

1) W. J. Davies and T. A. Mansfield, "Abscisic Acid," ed. by F. T. Addicott, Praegar, New York, 1983, p. 237.

2) G. Sembdner, W. Dathe, V. I. Kefeli and M. Kutáček, "Plant Growth Substances 1979," ed. by F. Skoog, Springer-Verlag, Berlin, 1980, p. 254.

3) B. V. Milborrow, "Plant Growth Substances 1979," ed. by F. Skoog, Springer-Verlag, Berlin, 1980, p. 262.

4) B. R. Loveys and B. V. Milborrow, Aust. J. Plant Physiol., 8, 571 (1981).

5) B. V. Milborrow and G. T. Vaughan, Aust. J. Physiol., 9, 361 (1982).

6) N. Takeda,.K.-I. Harada, M. Suzuki, A. Tatematsu, N. Hirai and K. Koshimizu, Agric. Biol. Chem., 48, 685 (1984).

7) N. Takeda, K.-I. Harada, M. Suzuki and A. Tatematsu, Org. Mass Spectrom., 20, 236 (1985).

8) N. Takeda and A. Tatematsu, Mass Spectrosc., 33, 51 (1985).

9) N. Takeda, K.-I. Harada, M. Suzuki and A. Tatematsu, Mass Spectrosc., 33, 59 (1985).

10) D. F. Hunt, J. Shabanowitz, F. K. Botz and D. A. Brent, Anal. Chem., 49, 1160 (1977). 
11) K. Koshimizu, M. Inui, H. Fukui and T. Mitsui, Agric. Biol. Chem., 32, 789 (1968).

12) N. Hirai and K. Koshimizu, Agric. Biol. Chem., 47, 365 (1983).
13) N. Hirai, H. Fukui and K. Koshimizu, Phytochemistry, 17, 1625 (1978).

14) Y. Y. Lin and L. L. Smith, Biomed. Mass Spectrom., 6, 15 (1979). 